J. Clin. Chem. Clin. Biochem.

Vol. 16, 1978, pp. 323-327

\title{
Comparative Studies on the Radioimmunological Determination of Carcinoembryonic Antigen in Tumour Tissue
}

\author{
By $C$. Wagener and $H$. Breuer
}

Institut für Klinische Biochemie, Universität Bonn

(Received Juli 30/December 2, 1977)

Herrn Professor Dr. Dr. Ernst Schütte zum 70. Geburtstag gewidmet

Summary: Human carcinoembryonic antigen (CEA) was measured in perchloric acid extracts from 9 malignant gastrointestinal tumours, using two different radioimmunological methods (Hoffmann-La Roche and CEA-IRESORIN). When standard curves were set up, quantitative differences in the degree of inhibition were found between the standards from the two manufacturers. In the Hoffmann-La Roche assay the CEA binding curves of all tumour extracts ran parallel with the standard. However, when the CEA-IRE-SORIN assay was applied two of the nine tumours exhibited different slopes. In one case, using the CEA-IRE-SORIN method, various parts of the tumour exhibited binding curves with non-parallel slopes. The present results suggest that radioimmunologically heterogeneous CEA occurs in different gastrointestinal tumours as well as in various parts of the same tumour.

\section{Vergleichende Untersuchungen zur radioimmunologischen Bestimmung von carcinoembryonalem Antigen im Tumor- gewebe}

Zusammenfassung: In Perchlorsäureextrakten aus neun gastrointestinalen Tumoren wurde das carcinoembryonale Antigen des Menschen (CEA) mit Hilfe zweier radioimmunologischer Methoden (Hoffmann-La Roche und CEAIRE-SORIN) bestimmt. Bei der Aufstellung von Standardkurven ergaben sich quantitative Unterschiede zwischen den Standards der beiden Hersteller in Bezug auf vergleichbare Hemmungen. Bei Verwendung von Hoffmann-La Roche-Reagenzien verliefen die Bindungskurven für CEA in allen neun Tumorextrakten zum Standard parallel; mit der CEA-IRE-SORIN-Methode zeigten sich in zwei von neun Fällen unterschiedliche Kurvenverläufe. Bei mehreren Tumoren wurde CEA in verschiedenen Gewebsanteilen bestimmt. In einem Fall wurden mit der CEA-IRE-SORINMethode an verschiedenen Stellen unterschiedliche Kurvenverläufe beobachtet. Die vorliegenden Befunde sprechen dafür, daß sowohl in verschiedenen gastrointestinalen Tumoren als auch in verschiedenen Anteilen desselben Tumors CEA vorkommen kann, welches sich radioimmunologisch heterogen verhält.

\section{Introduction}

Human carcinoembryonic antigen (CEA) was first described in colonic carcinomas by Gold \& Freedman (1). Using radioimmunological methods, CEA has been demonstrated in ng-amounts in plasma or serum $(2,3)$, and in extracts from normal and malignant tissues $(4,5)$. Although CEA showed biochemical heterogeneity $(6,7)$, many authors found no qualitative differences between different standard preparations and extracts from malignant tumours in radioimmunoassays $(6,8,9)$. Recently, however, differences have been demonstrated between various standard preparations with respect to qualitative and quantitative behaviour in radioimmunoassay (10-13). Comparing a CEA standard preparation with a tumour extract from a patient, suffering from colonic cancer, $V r b a$ et al. (11) observed differences in the binding of the standard and the patient's CEA. Furthermore, standard preparations from different individuals, prepared by identical isolation methods, can lead to different plasma concentrations (13). In urine qualitative differences between CEA standard and sample have been described, depending on the antiserum used in the assay (14).

There seem to exist considerable differences between different CEA standards and antisera; moreover, CEA in plasma and tumour extracts may show radioimmunolog- 
ical heterogeneity, depending on the standard and the antiserum used. Therefore, in the present study, two commercially available test kits for the determination of CEA in extracts from gastrointestinal tumours were compared. It was found that differences with respect to the qualitative behaviour of CEA in radioimmunoassay exist between various tumours and also within the same tumour.

\section{Materials and Methods}

1-6 $\mathrm{g}$ tissue from malignant tumours of the gastrointestinal tract was dissected from normal tissue, frozen and stored at $-20^{\circ} \mathrm{C}$ until use. Each specimen was examined histologically to verify diagnosis. Radioimmunological determinations of CEA were performed with two commercially available test kits (HoffmannLa Roche, Basel, Switzerland, and CEA-IRE-SORIN [CIS], distributed by Isotopendienst West, Frankfurt/Main, F. R. Germany). Tissue was homogenised with an Ultra-Türax, type TP-18-10, Janke \& Kunkel, Staufen i. Breisgau.

The homogenisation and extraction procedures were performed at $4^{\circ} \mathrm{C}$. The tissue was sliced and homogenised in $4 \mathrm{ml}$ saline per $\mathrm{g}$ tissue; an equal volume of $1.2 \mathrm{~mol} / 1$ perchloric acid (15) was added dropwise to the homogenate during agitation in a Vortex mixer. The mixture was agitated for $30 \mathrm{~min}$ and centrifuged at $5000 \mathrm{~g}$ for $30 \mathrm{~min}$ at $4^{\circ} \mathrm{C}$. The supernatant was kept for further analysis.

For the determination of CEA by the Hoffmann-La Roche assay, the supernatant was diluted in perchloric acid extracts from a pool of normal EDTA-plasmas. For this purpose, plasma from healthy non-smokers with an age of less than 40 years was diluted $1: 5$ in saline and extracted in $0.6 \mathrm{~mol} / 1$ perchloric acid. Before use the pools were checked for CEA content. The diluted tumour extracts were dialysed against repeated changes of deionized water until the conductance of the water was $1 \mu \mathrm{S}$, and finally against $0.01 \mathrm{~mol} / 1$ ammonium acetate buffer, $\mathrm{pH}$ 6.8. The non-dialysable residue was tested in the radioimmunoassay for CEA content. The standard curve was performed with the non-dialysable residue of the dialysed perchloric acid extract of the normal plasma pool. In order to obtain more points in the lower concentration range of the standard curve, the Hoffmann-La Roche standard $\left(C E A_{R}\right)$ was diluted in $0.1 \mathrm{~mol} / \mathrm{l}$ borate buffer, $\mathrm{pH} 8.4$, containing $10 \%$ plasma from a plasma pool of normal blood donors with the blood group $A$ Rhpos. This buffer was recieved from Hoffmann-La Roche, Basel, Switzerland, and is identical with the buffer in which CEA $A_{R}$ is dissolved. The radioimmunoassay was performed according to the instructions of the manufacturer.

For the determination of CEA by the CIS radioimmunoassay, the undiluted perchloric acid tumour extracts were dialysed against deionized water as described above and finally against $0.02 \mathrm{~mol} / \mathrm{l}$ veronal buffer, $\mathrm{pH}$ 8.3. Double dilutions of the nondialysable residue were made in the same buffer. $50 \mu$ of the dilutions were taken for the assay. $50 \mu \mathrm{l}$ of the normal pool plasma mentioned above were added to the standard tubes and to the tubes containing the dilutions of the tumour extract. Addition of antiserum and I $\left.^{125} I\right] C E A$, and the separation of free and bound antigen were performed according to the instructions of the manufacturer.

For the comparison of the standards and for testing the tumour extracts for maximum inhibition in a combined Hoffmann-La Roche-CIS-system, the CIS antiserum was dissolved in $0.1 \cdot \mathrm{mol} / \mathrm{I}$ borate buffer, obtained from Hoffmann-La Roche. A titration curve was performed using the Hoffmann-La Roche-assay system. The titre of the antiserum required to bind $25 \%$ of the $1{ }^{125}$ I]CEA from Roche was used in the radioimmunoassay.

The response variable $\frac{B-N}{B_{0}-N}$ was chosen, where $B$ is the number

of counts in the bound fraction of the sample or the standard,
$B_{o}$ is the number of counts in the bound fraction without addition of standard or sample, and $\mathbf{N}$ is the number of counts in the precipitate without addition of antiserum. The counting time was 5 min.

Standards were determined in triplicate and samples in duplicate. In each separate experiment, the tested extracts were analysed simultaneously with standards. Standard error of the duplicate or triplicate determinations was less than $\pm 5 \%$.

\section{Results}

The binding of the Hoffmann-La Roche standard (CEA) and of the CEA-IRE-SORIN standard (CEA ${ }_{C I S}$ ), using the Hoffmann-La Roche antiserum $\left(\mathrm{AS}_{\mathrm{R}}\right)$ and the CIS antiserum ( $A S_{C I S}$ ) are demonstrated in figure 1. As can be seen, the curves run parallel, but a higher amount of CEACIS was necessary to reach a comparable binding. To reach 0.50 binding, a 2.5 fold amount of $C_{C A}$ was needed as compared to $C E A_{R}$, when $A S_{R}$ was used. A 3.2 fold amount of CEACIs was necessary in comparison to $\mathrm{CEA}_{\mathrm{R}}$, with the antiserum from CIS.

CEA was determined in 9 tumours of the human gastrointestinal tract by the two different methods. Using the CIS assay, the binding of CEA in the extracts from two tumours was clearly different from the binding of the standard (figs. 2 and 3). In both cases, the binding curves of the tumour extracts are steeper

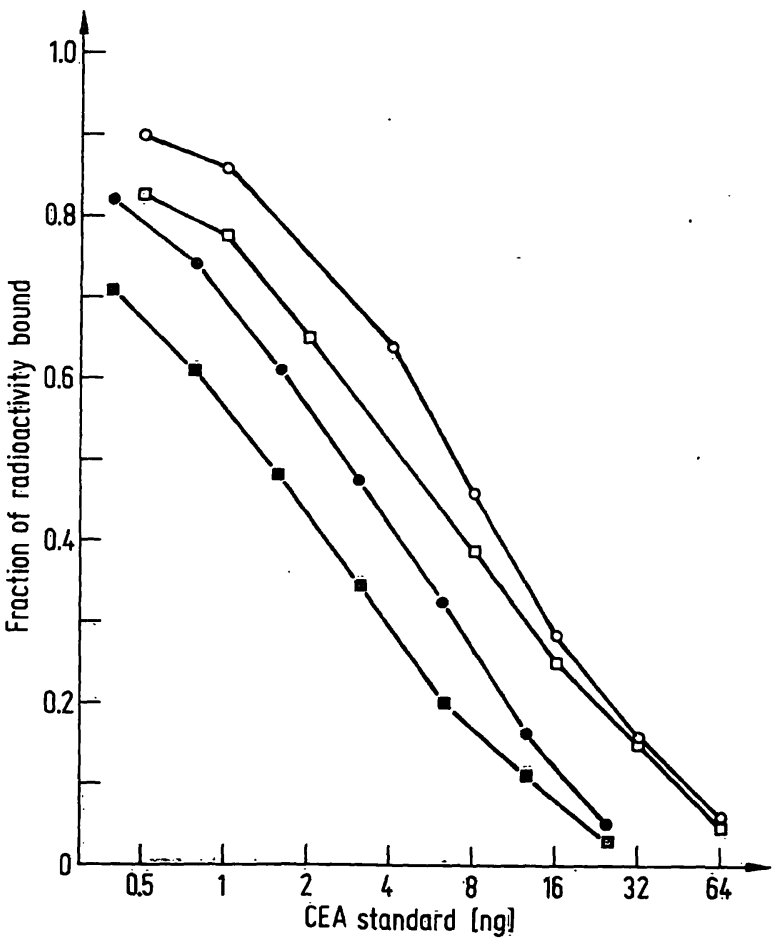

Fig. 1. Binding curves of two commercially available CEA standards.

○-O CEA-IRE-SORIN

- Hoffmann-La Roche

Antiserum: Hoffmann-La Roche

:-

- - Hoffmann-La Roche

Antisērum: CEA-IRE-SORIN 


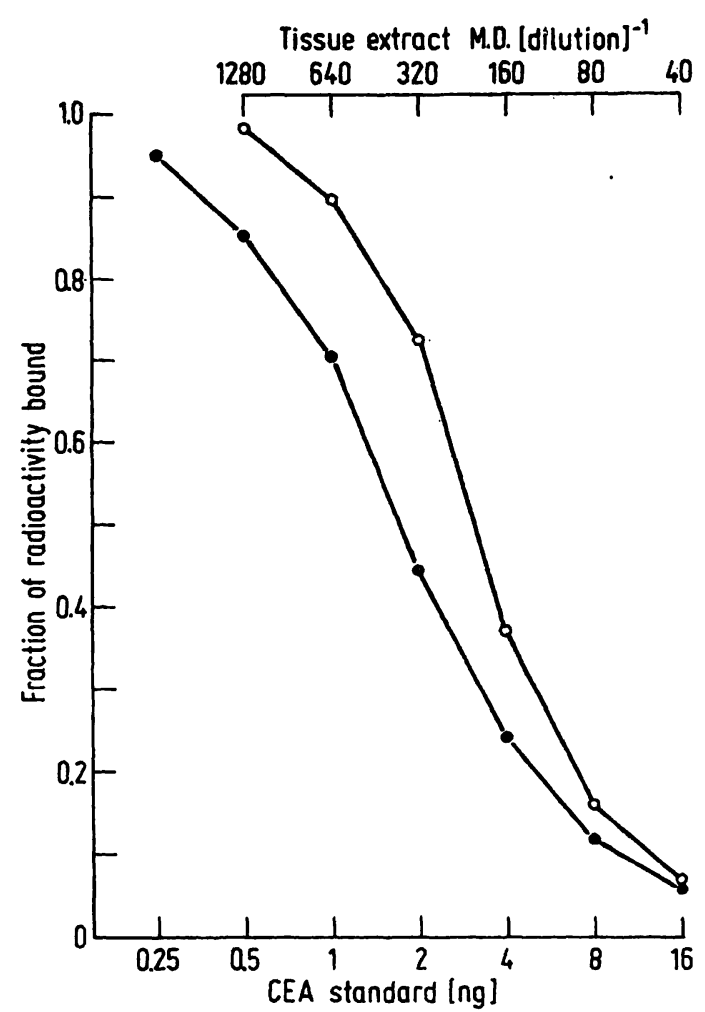

Fig. 2. Binding curves of a perchloric acid extract from a colonic carcinoma and of the CIS standard in the CIS radioimmunoassay.

o-o colonic carcinoma M.D.

$\bullet$ CIS standard

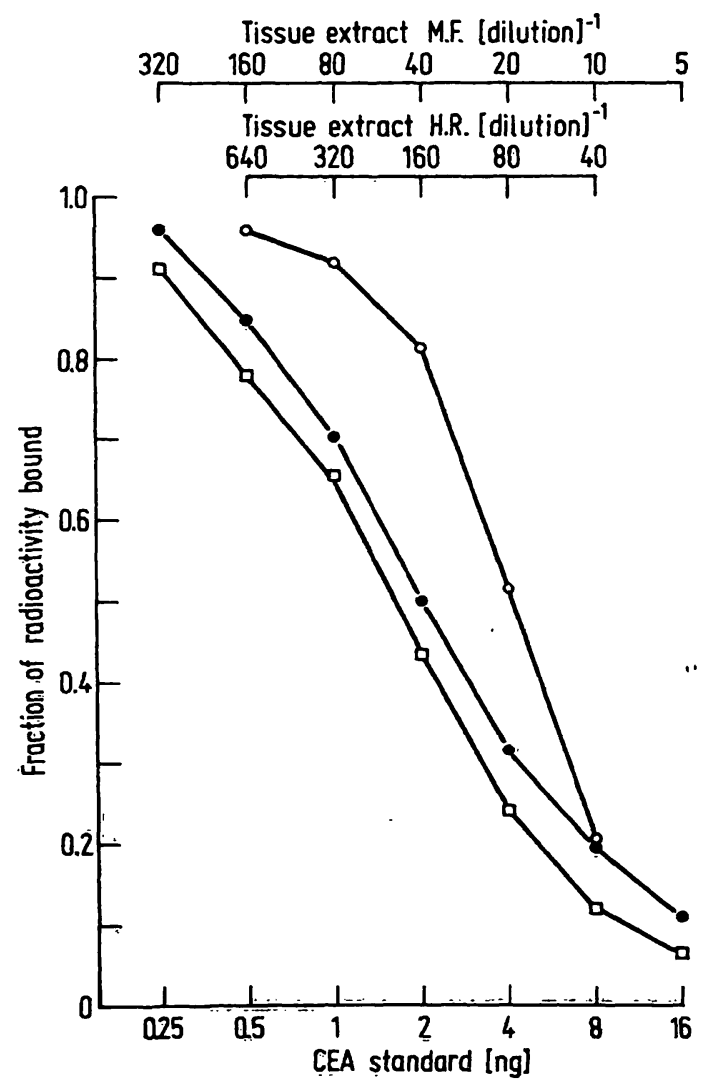

Fig. 3. Binding curves of perchloric acid extracts from a colonic and a gastric carcinoma and of the CIS standard in the CIS radioimimunoassay.

o-o colonic carcinoma H.R. (center)

D- gastric carcinoma M.F.

$\bullet$ CIS standard

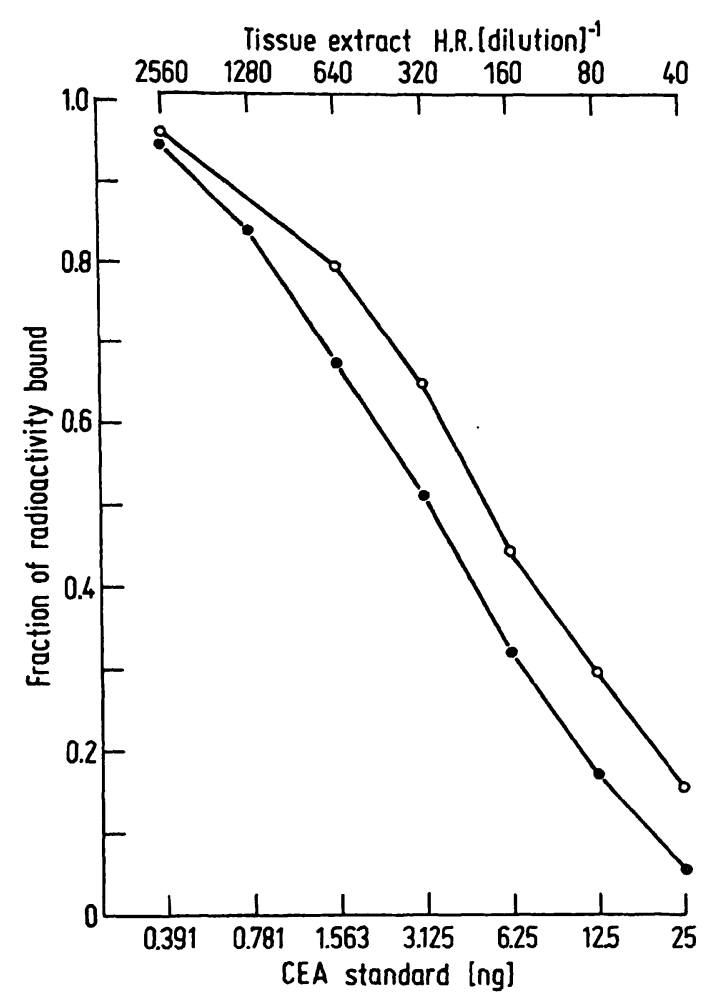

Fig. 4. Binding curves of a perchloric acid extract from a colonic carcinoma and of the Hoffmann-La Roche standard in the Hoffmann-La Roche radioimmunoassay.

o-o colonic carcinoma H.R. (center)

- - Hoffmann-La Roche standard

than the binding curves of CEA ${ }_{C I S}$. In the experiment demonstrated in figure 3 , two tumour extracts were assayed simultaneously. In the case of a gastric carcinoma, the binding curve runs parallel with the standard curve, whereas in the case of a colonic carcinoma (H.R.) the slope of the binding curve is clearly different. In the Hoffmann-La Roche assay, the binding curve of the same tumour extract was parallel to the $C E A_{R}$ standard curve (fig. 4).

The colonic carcinoma H.R. mentioned above was about $12 \mathrm{~cm}$ in diameter, histologically anaplastic and exhibited a central necrosis. The plasma concentration in this case, as determined by the Hoffmann-La Roche assay, was about $1000 \mu \mathrm{g} / 1$.

With regard to the different behaviour of the perchloric acid extract of this tumour in comparison with CEA $\mathrm{CIS}_{\mathrm{S}}$ in the CIS assay, tissue specimens were taken from the central necrotic and from the peripheral tumour parts and processed separately. The binding curves of the perchloric acid extracts from the peripheral and central tissue specimens in the CIS assay are shown in figure 5. The slope of the extract from the central tissue specimen is steeper than the slope of the extract from the peripheral tissue. The same extracts were also analyzed in the Hoffmann-La Roche assay (fig. 6). No difference with respect to the slopes of the binding curves could be demonstrated between the extracts from the central and peripheral tumour parts. 


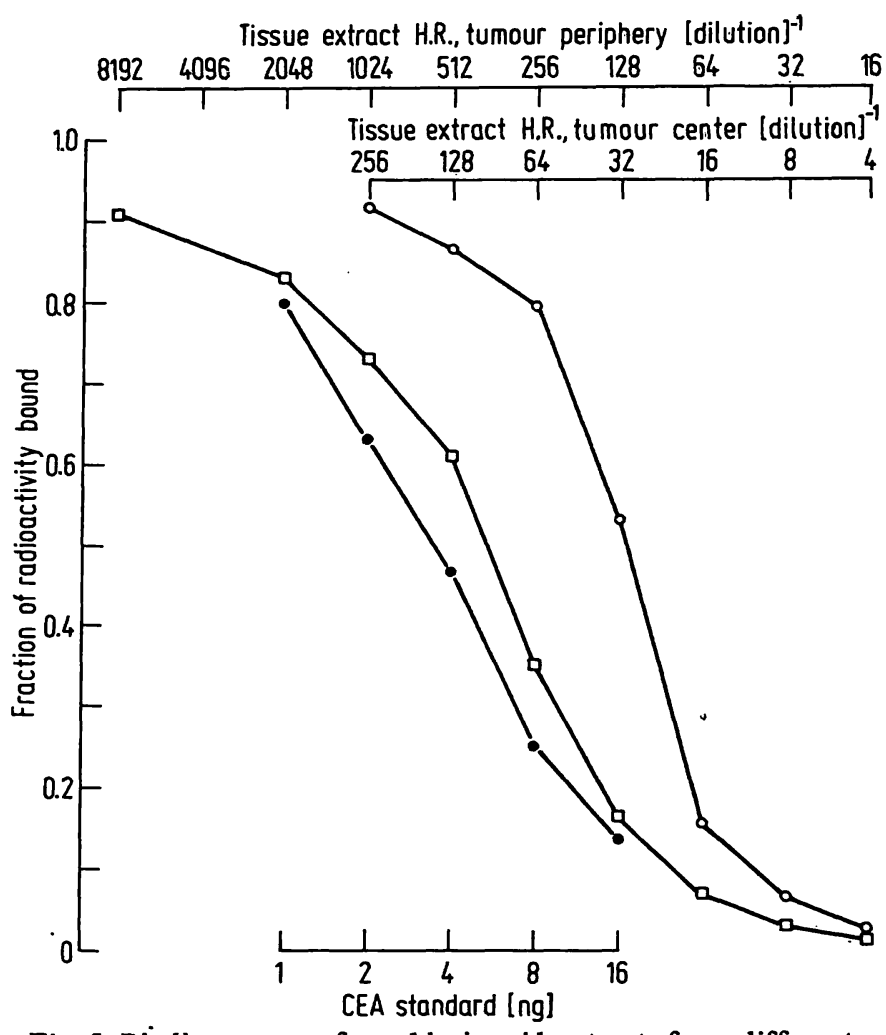

Fig. 5. Binding curves of perchloric acid extracts from different parts of a colonic carcinoma and of the CIS standard in the CIS radioimmunoassay.

o-o colonic carcinoma H.R. (center)

o- c colonic carcinoma H.R. (periphery)

$\bullet$ CIS standard

Tissue extract H.R. tumour periphery [dilution $]^{-1}$ $\begin{array}{lllllll}40960 & 20480 & 10240 & 5120 & 2560 & 1280 & 640\end{array}$ Tissue extract H.R., tumour center [dilution] ${ }^{-1}$

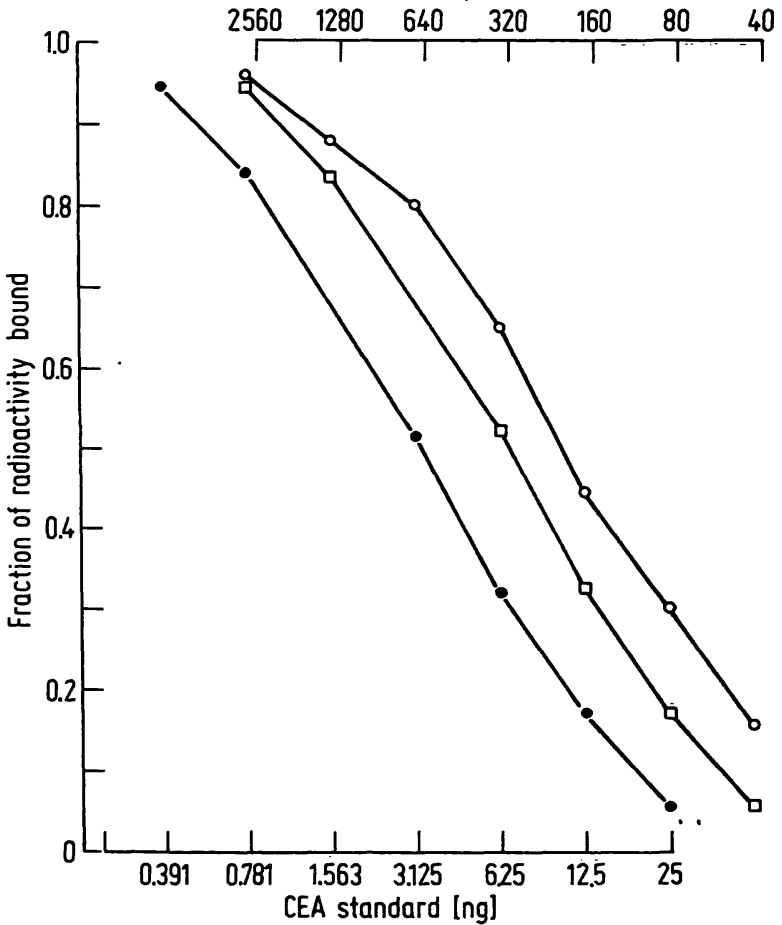

Fig. 6. Binding curves of perchloric acid extracts from different parts of a colonic carcinoma and of the HoffmannLa Roche standard in the Hoffmann-La Roche radioimmunoassay.

O- o colonic carcinoma H.R. (center)

$\square-\square$ colonic carcinoma H.R. (periphery)

- Hoffmann-La Roche standard
The tumour extracts were checked for minimum binding (maximum inhibition) at the lower dilution ranges with both assays and with a combined assay with $\left[{ }^{125} \mathrm{I}\right] \mathrm{CEA}$ from Roche and $\mathrm{AS}$ CIS . In no case was minimum binding significantly different from the unspecific binding.

\section{Discussion}

In comparison with $\mathrm{CEA}_{\mathrm{R}}$, a higher amount of $\mathrm{CEA}_{\mathrm{CIS}}$ was needed to reach the same binding of $\left[{ }^{125} \mathrm{I}\right] \mathrm{CEA}$ in the radioimmunoassay. This was true for both antisera. According to the information given by the manufacturer CEA $_{\text {CIS }}$ was prepared from liver metastases of colonic carcinomas, using the Gold technique (16). Quantitative differences between $C E A_{\mathbf{R}}$ and standards prepared according to the Krupey-Gold technique (16) were also described by Ashman et al. (10) and Vrba et al. (11). There are several possible explanations for these quantitative differences. Persijn \& Korsten (14) emphasized the importance of an exhaustive dialysis of the CEA preparations in order to exclude salts that would cause quantitative differences between CEA standard preparations. A second and third point was stressed by Newman et al. (17). A variable water content remaining in the standard preparations after lyophilisation might also be responsible for quantitative differences. Moreover varying degree of damage, caused by autolysis, can markedly lessen the antigenic potency of a preparation if ion exchange chromatography or gel-block electrophoresis are omitted in the isolation procedure. According to Edgington et al. (13) the antigen binding capacity depends at least in part on the isolation procedure.

We found no qualitative differences between the two CEA standards. This finding corresponds to the results of Ashman et al. (10), but is in conflict with Vrba et al. (11) who described qualitative differences between $\mathrm{CEA}_{\mathrm{R}}$ on one hand and three standards from different sources (Gold/Montreal; Todd/Duarte, Calif.; CEABritish, Med. Res. Council of U.K.) on the other hand. In contrast to Vrba et al. (11), in the present study the Hoffmann-La Roche standard curve was measured in a wider concentration range.

Qualitative differences were found between $C E A_{C I S}$ and two out of nine perchloric acid extracts from gastrointestinal tumours, using the CIS radioimmunoassay. Furthermore, a radioimmunological heterogeneity of CEA within the same tumour was demonstrated for the first time. The occurrence of radioimmunologically different CEA species within the same tumour may be due either to the synthesis of different CEA species or to partial degradation of the CEA molecule. The latter possibility seems more likely, since one of the two tissue specimens was taken from the necrotic tumour center. This conclusion is supported by the fact that the CEA content of the central tumour part was only $1 \mu \mathrm{g} / \mathrm{g}$ 
wet weight, whereas the peripheral part contained $41 \mu \mathrm{g} / \mathrm{g}$ wet weight. The concept that partially degraded CEA in necrotic tissue may exhibit different binding curves may explain the findings of Vrba et al. (11) who described heterogeneity of serum CEA mainly in patients with very high CEA serum content.

So far, we have studied the radioimmunological behaviour of CEA in perchloric acid extracts from more than 50 gastrointestinal carcinomas by the Hoffmann-La Roche assay. None of these tumours showed qualitative radioimmunological differences between standard and tumour CEA.

There are various possible explanations for these findings. The choice of the antiserum plays an important role in the detection of radioimmunological differences between different CEA preparations. Our results indicate that in some antisera there may exist antibody populations which recognize different antigenic determinants on distinct CEA species. These antigenic determinants differ in their affinity for the antibodies. Thus, the demonstration of radioimmunological differences in the slope of the binding curves depends on the CEA preparations or the antisera used in the assay. A deficiency of the antibody population(s) capable of recognizing the antigenic determinant(s) with different affinities or a lack of these determinants on the labelled CEA prevents the demonstration of radioimmunological differences between the different CEA species.

The standard isolation procedures and the absorption of the antisera are different in both assays. According to the information of the manufacturer, CEA-CIS was prepared by the method of Krupey et al. (16). A different isolation procedure was described by Newman et al. (Hoffmann-La Roche, Nutley, (17)), who stressed the importance of an additional purification step (ion exchange) in the isolation procedure in order to exclude material damaged by autolysis. The CIS antiserum was raised in rabbits. The immunogen was the same as that used for the standard and the tracer. The antiserum was absorbed against extracts from human spleen and lung. Hansen and co-workers (Hoffmann-La Roche, Nutley, (18)), described an antiserum, which was induced in goats against a partially purified perchloric acid extract from colonic carcinoma (F-1). This antiserum was monospecific without further absorption when tested against perchloric acid extracts from colonic carcinomata and purified CEA in immunodiffusion.

In both radioimmunoassays and in a combined assay assay using labelled $C E A_{R}$ and $A_{C I S}$, minimum binding was reached by all tumour extracts at lower dilution. Hence, it follows that masking or loss of antigenic determinants in comparison with the CEA standards was not demonstrable.

\section{Acknowledgement}

The authors wish to thank Prof. H. Rohr and Prof. W. Wessel for supplying tumour tissue. The technical assistance of Mrs. Monika Denner and Sigrid Nissen is gratefully acknowledged.

\section{References}

1. Gold, P. \& Freedman, S. O. (1965), J. Exp. Med. 121, 439462.

2. Thomson, D. M. P., Krupey, J., Freedman, S. O. \& Gold, P. (1969), Proc. Natl. Acad. Sci. USA 64, 161-167.

3. Lo Gerfo, P., Krupey, J. \& Hansen, H. J. (1971), N. Engl. J. Med. 285, 138 1141 .

4. Martin, F. \& Martin, M. S. (1972), Int. J. Cancer 9, 641647.

5. Khoo, S. K., Warner, N. L., Lie, J. T. \& Mackay, I. R. (1973), Int. J. Cancer 11, 681-687.

6. Coligan, J. E., Henkart, P. A., Todd, C. W. \& Terry, W. D. (1973), Immunochemistry I0, 591-599.

7. Banjo, C., Shuster, J. \& Gold, P. (1974), Cancer Res. 34, 2114-2121.

8. Pusztaszeri, G. \& Mach, J.-P. (1973), Immunochemistriy 10, 197-204.

9. Dyce, B. J. \& Haverback, B. J. (1974), Immunochemistry 11, $423-430$.
10. Ashman, L. K., Ludbrook, J. \& Marshall, V. R. (1975), Br. Med. J. 2, 721-724.

11. Vrba, R., Alpert, E. \& Isselbacher, K. J. (1975), Proc. Natl. Acad. Sci. USA 72, 4602-4606.

12. Plow, E. F. \& Edgington, T. S. (1975), Int. J. Cancer 1S, 748-761.

13. Edgington, T. S., Plow, E. F., Chavkin, C. I., Deheer, D. T. \& Nakamura, R. M. (1976), Bull. Cancer 63, 673-688.

14. Persijn, J.-P. \& Korsten, C. B. (1976), this J. 14, 377-387.

15. Krupey, J., Gold, P. \& Freedman, S. O. (1968), J. Exp. Med. $128,387-398$.

16. Krupey, J., Wilson, T., Freedman, S. O. \& Gold, P. (1972), Immunochemistry $9,617-622$.

17. Newman, E. S., Petras, S. E., Georgiadis, A., \& Hansen, H. J. (1974), Cancer Res. 34, 2125-2130.

18. Hansen, H. J., Hager, H. J., Cohen, H. \& Krupey, J. (1971), Clin. Res. 19, 953.
Prof. Dr. Heinz Breuer Institut f. Klinische Biochemie der Universität, Venusberg D-5300 Bonn 1 
